\title{
Operation management mode and system of aerospace information system based on Cloud Computing
}

\author{
Junwei Wan ${ }^{+}$and Hongyan Chen \\ Beijing Institute of Tracking and Telecommunicaitons Technology, Beijing 100094, China
}

\begin{abstract}
Cloud computing technology has become the preferred option for next generation space test information system. Aiming at the limitation of the existing distributed and vertical operation management mode of aerospace test information system, The centralized and flat operation management mode based on cloud computing is put forward, provide cloud- Administration- terminal operation management technology system, also provide the managed object, communication network, cloud management center and users of four parts based on the typical operation management system architecture of cloud computing. Furthermore, operation management model based on cloud computing compared with the traditional mode, a high rate of resource utilization, operation management, information sharing and easy fusion efficiency. At the same time, the platform also brings troubleshooting difficulty and high availability of the increased demand, operation management system process needs to be optimized and other specific challenges.
\end{abstract}

Keywords: Cloud computing; aerospace test; operation management; vertical; flat.

\section{Introduction}

Operation management system is the support system of aerospace test information system, It is an important guarantee for the efficient and orderly operation of aerospace test information system[1,2].The major functions Include the system operation monitoring, user access management and resource scheduling optimization functions, In order to meet the daily operation, task test information system implement situation analysis and evaluation, resource allocation and scheduling, the ability of monitoring and tuning requirements[3].

At present, the management system of the spaceflight test information system is based on the management system, which is divided into several categories, such as measurement and control[4], measurement, communication, weather and service, distributed vertical management model. Existing problems: Respective build operation management platform, low resource utilization[5]; The operation management information is scattered, Sharing fusion difficult; Management multi-level, low management efficiency.

In recent years, the rapid development of new technologies such as cloud computing, big data, intelligence and other information technology, the development of information systems into a higher level of the times[6,7]. Because of cloud computing has many technical characteristics and application advantages, such as self-service, ubiquitous access, location independence, high flexibility and capacity measurement, It provides an opportunity for the development of the aerospace test information system in the aspects of system architecture expansion, system resource sharing, task capability generation and optimization of operation mode, Has become the next generation of aerospace test information system priority.

The application of cloud computing technology will not only change the business model of the current space test mission, but also change the operation and management mode of aerospace test information

\footnotetext{
Corresponding author.Tel.: +86 13811440720; fax: +01066361034

E-mail address: child_smile@163.com.
} 
system. This paper starts with the idea of cloud computing, the operation management mode of aerospace test information system is discussed, they proposes architecture and the system analysis, and compared with the traditional operation mode has the advantages and challenges.

\section{Analysis of traditional vertical operation management mode}

At present, the management system of spaceflight test information system is constructed by the distributed vertical management mode, The basic architecture is shown in Figure 1.

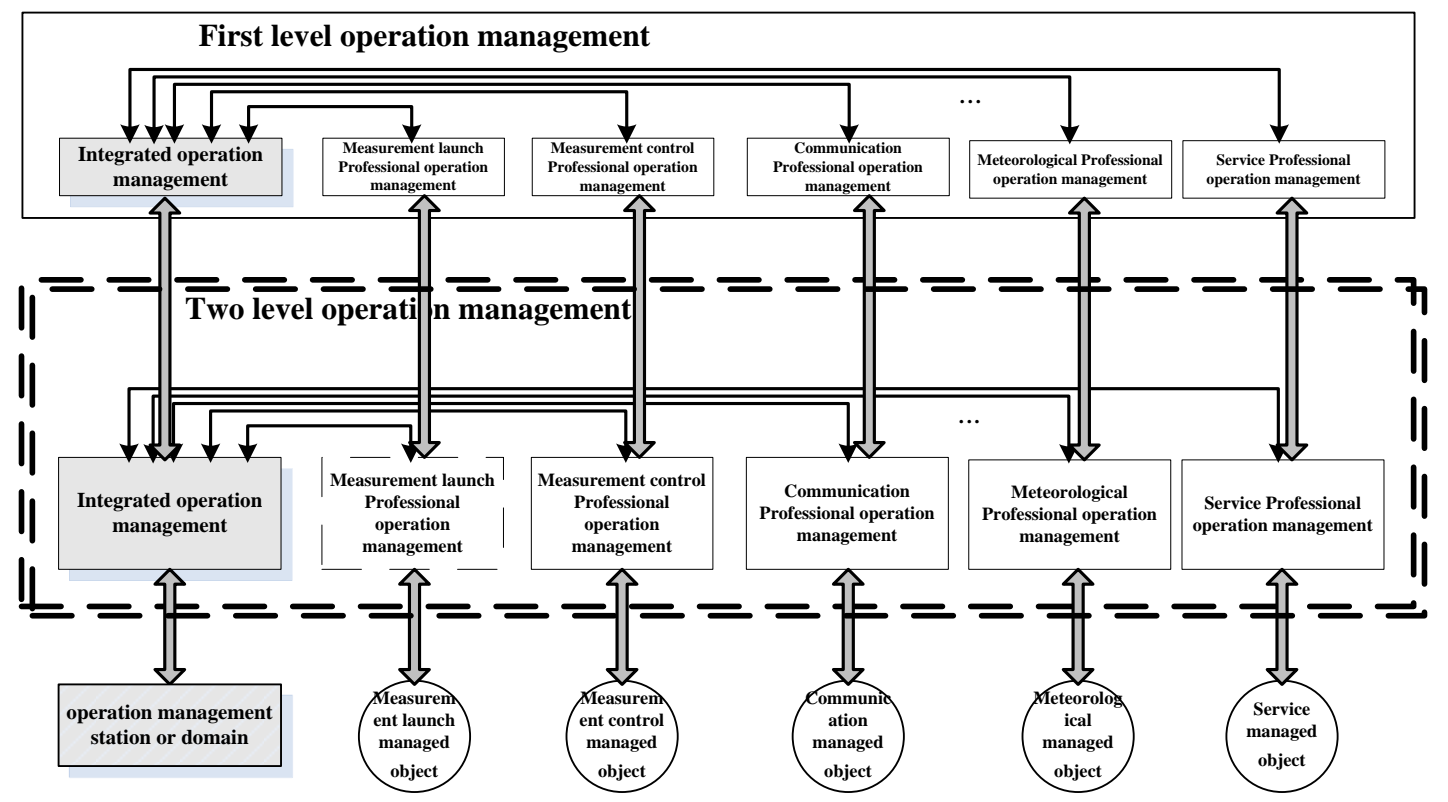

Fig.1: The basic architecture of vertical operation management system

The vertical management mode, according to the organization at all levels of operation and management. As a headquarters level setting operation management, each unit shall set up two levels of operation and management, set up substation operation management department station[8]. Operation and management at all levels to set up the integrated operation management and measurement, measurement and control, communications, meteorology and service management, Comprehensive management of the implementation of the overall management, professional operation management for the various business systems to achieve fine management.

At the same time, all levels of professional management and management through the interaction of network management information to form a cross vertical management relationship: Vertically, the Department of the station operation management information submitted to subordinate units of the two level of operation and management, each unit of the two level of operation and management of the management information reported to the level of operation and management; Horizontally, the professional management of the operation of the integrated management of the operation of the professional management information forwarded[9].

The distributed vertical management model is more suitable for the organization and management mode of the current space test task, but it has many limitations:

1) At all levels, professional management software and hardware platforms are generally their own construction and maintenance. First of all, the problem of repeated construction, the efficiency of resource utilization is not high; Secondly, the maintenance and management of decentralized, uneven level of management, personnel and quality is difficult to protect; Third, all levels of professional management interface complex, difficult to unify standards, is not conducive to interoperability[10].

2) The operation and management of information scattered in all levels of the professional operation and management, the need for information exchange and sharing through the network, sharing is difficult, the sharing of information is limited, the operation and management of the overall situation, such as the whole system resource allocation, fault location diagnosis support is limited. 
3) For the safety and liability considerations, managers are often difficult to cross unit, cross major remote operation management, operation and management flexibility is limited, professional management personnel can not get to play the greatest degree.

\section{Operation management model based on Cloud Computing}

In view of the problems existing in the traditional operation management, based on the concept of cloud computing, we can improve the traditional operation management structure from the following points, and realize the transformation of the traditional management mode to clouding management mode:

1) Create operation management support cloud platform to achieve integration of operation and management support.

In the management of software and hardware support layer, the use of infrastructure as a service (IAAS) and platform as a service (PAAS) technology, building operation management support cloud platform, Integration of hardware and platform resources to support operation management system, to achieve the unification of the professional operation management, integrated operation management support platform for carrying and centralized maintenance, No longer in accordance with the traditional way, according to the unit, professional construction management support platform.

2) Construction operation management application pool of resources, realize the operation and management functions of service.

In the operational management business application layer, using software as a service (SAAS) technology. In the "cloud" concept, Develop and integrate all kinds of operation management software, tools and operation management process. Creating a run management application resource pool, The operation management function as a customizable service in the form of WEB to provide management users.

3) Establish and manage data sharing chain, Centralized management information.

According to the management area, in order to achieve the principle of proximity, the relative concentration of various types of operation and management information, and through the information synchronization mechanism to achieve exchange management and exchange of information between different regions. The operation management information is no longer scattered and stored as the traditional hierarchical vertical management mode, but is centralized to the cloud for unified storage, processing and application.

\section{Operation management system based on Cloud Computing}

In the cloud management mode, the operation management system will adopt the cloud pipe end technology system, as shown in Figure 2.

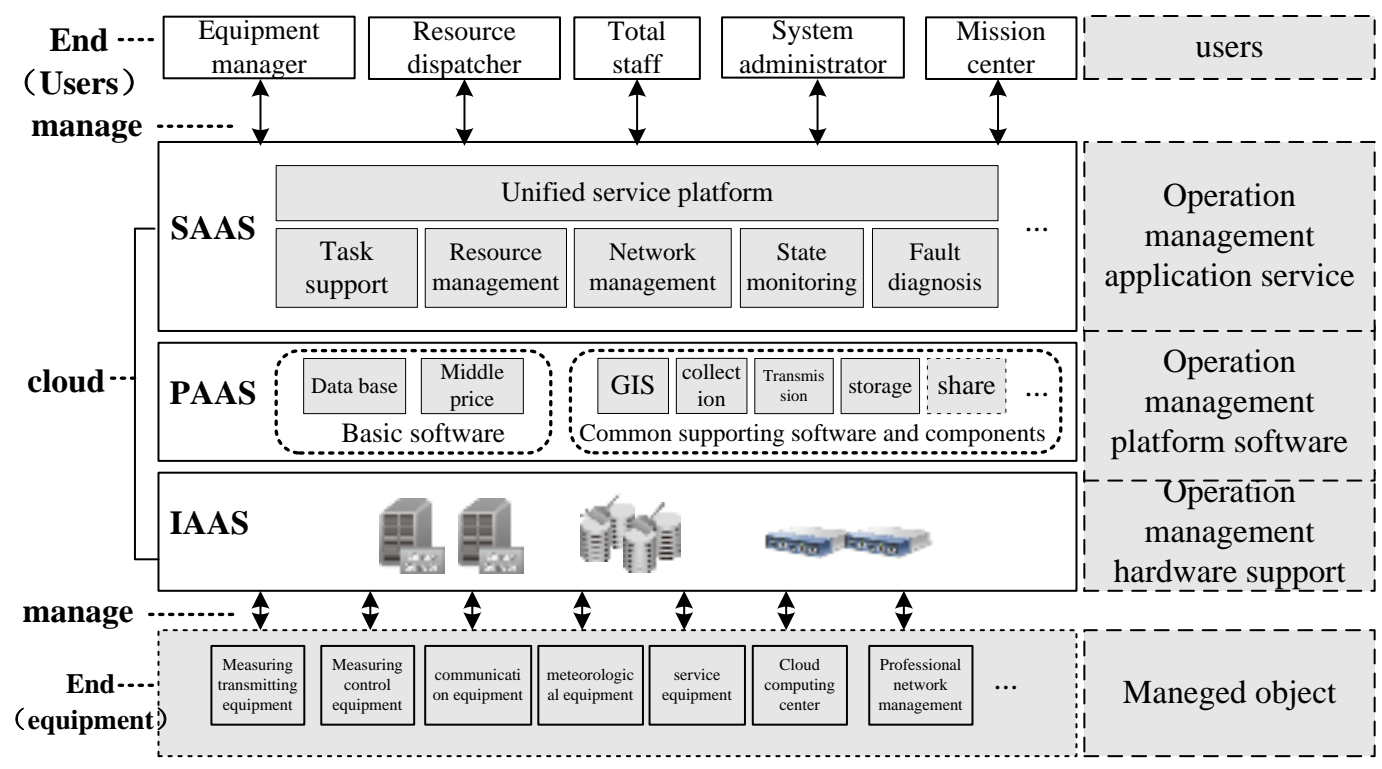

Fig.2: Cloud management mode of operation and management system 
1) End: divided into device and client. The device that managed object, including all kinds of standard test, measurement and control, communications, meteorology, service, Cloud Computing Center (such as SNMP can provide a standard management interface device) or non standard (management information provided by the proprietary interface or protocol) devices and resources. The user, that is the object of running the management system application services, including equipment management, resource scheduling, overall, system management and other personnel and mission centers and other entities.

2) Pipe: Mainly refers to the network communication facilities of various types of cloud terminal. Among them: the device side, can not use the traditional network access mode, can consider the use of wireless networks, networking and other means of access. Users, in addition to the traditional fixed access mode, can consider the use of wireless mobile network access, remote mobile management.

3) Cloud: cloud management server, It can be divided into three levels, the operation management hardware support layer, the operation management platform software layer and the application layer. Among them, the operation and management of hardware support layer, using IAAS (infrastructure-as-a-service) construction, for each professional operation management, integrated operation management unified distribution calculation, storage and cyber source, to achieve a unified operation and management and maintenance of hardware support bearing; Operation management platform software layer, using PAAS (platform as a service), provide the basis for the operation and management of the software application service layer (database, middleware) and common supporting software and components (such as the GIS tools, unified collection, transmission, sharing components); The operation and management of the application service layer, using SAAS (software as a service), with customized services to all kinds of operation and management of users provide all kinds of operation and management functions, including task support, resource management, network management, state monitoring, fault diagnosis etc..

Cloud operation management mode, the operation management system will be managed by the main object, the communication network, cloud operation management center and the user is composed of 4 parts, as shown in figure 3 .

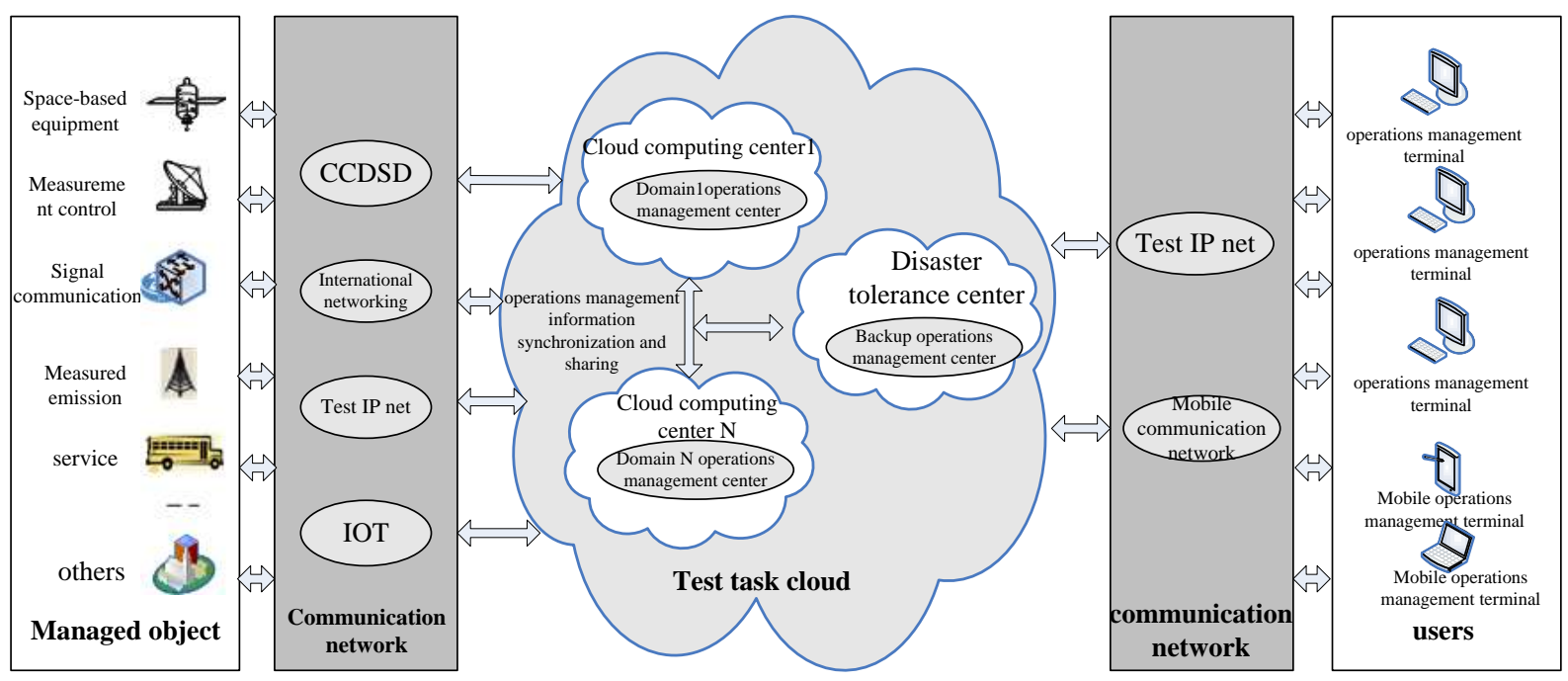

Fig.3: Composition of operation management system in cloud management mode

1) Managed objects: measurement, measurement, communication, service and other types of days, the foundation of the test equipment and resources.

2) Communication network: the access network of the managed object mainly includes the IP network, the Internet, the Internet of things and the CCSDS network; The user's access network mainly includes IP network and mobile communication network.

3) Cloud operation management center: Sub region, according to the peer-to-peer model to build the corresponding cloud management center, The cloud operation management center is responsible for collecting the information of the objects in the area, and through the operation management data sharing chain, to achieve the exchange and sharing of management information between different regions. Each operation management center (including the operation and management of the backup center) has all the 
functions of the operation and management of all equipment management information. Can achieve multi run management center load sharing, and disaster recovery for each other, the operation and management of the user can $\log$ on to any one of the most recent operation and management center, authorized by the operation and management.

4) Users: including fixed access users and mobile users, mobile management users to PAD, portable machines and other mobile devices, through the mobile communication network access to the management center for mobile operation management.

\section{The advantages and challenges of cloud computing based management model}

Compared with the traditional vertical operation management mode, the management mode based on cloud computing has the following advantages:

1) Due to the adoption of IaaS technology, operation and management mode based on cloud computing, which can effectively eliminate the traditional mode of operation and management, professional management, integrated operation management hardware platform of their own construction and maintenance, low utilization rate of decentralized management of resources caused by dispersion of power. Moreover, the operation and management of cloud computing center support platform can make unified management by cloud, operation and management personnel only need to focus on operation and management of the business itself, without paying attention to the platform maintenance, realizing the separation of hardware and software support platform of operation management and operation management, which can effectively reduce the working pressure of the operation and management staff, improve the efficiency of the operation and management.

2) First of all, because of the use of PaaS and SaaS technology, operation and management mode based on cloud computing, standardization can realize the general operation and management functions and components, effectively solve the traditional professional operation and management at all levels and complex interface, the standard is difficult to unity, to achieve interoperability of complex problems; Secondly, to enhance the efficiency of the development and deployment of the operation management software, general operating management software can focus on R \& D, on-demand deployment, personalized operation management software can be divided into $\mathrm{R} \& \mathrm{D}$, co construction and sharing; Third, due to operation and management services can be provided to the user WEB operation management, operation management users in any network access points, according to the authorization to obtain whenever and wherever possible operation and management, operation management, which can cross unit, cross professional remote operation and management, can effectively improve the flexibility of operation and management.

3) Due to the centralized transportation information, so as to overcome the traditional management mode of operation and management of information sharing is difficult, dispersion, fusion of the shortcomings, and decentralized management mode for the centralized management mode, will be scattered on the cloud in a large number of service industry around, can centralized scheduling resource monitoring, etc. the operation management function effectively, reduce the level of management, flat management.

Compared with the traditional model, the advantages of cloud computing based operation management is obvious, but it also brings new problems and challenges:

1) Platform troubleshooting increased difficulty: After the adoption of cloud computing technology, the operation and management of the operation support platform from the physical environment into a virtual environment, increased virtualization layer, the physical layer and the logical layer from the fault troubleshooting more difficult. When running the management business system anomalies, it is necessary to clear the virtual server in which physical server, Which physical network switch interface access network, Even need to understand the network configuration on the virtual switch, In particular, the visibility of server and network boundary connectivity, If the information can not be effectively managed, it will not be able to effectively analyze and locate the fault.

2) Increased demand for high availability security: After the adoption of cloud computing model, the operation of management services and data are concentrated in the cloud, all of its business activities are 
dependent on the stable operation of the clouding, Any surprises in the cloud are likely to affect the normal operation of the operating management system, resulting in the operation management business can not be carried out properly.

3) The transport system needs to be optimized: Based on cloud computing, the construction, maintenance and service mode of the operation management system are quite different from the traditional one, It is necessary to establish a suitable operation management system to adapt to this change. In addition, the centralized management mode of cloud computing is obviously different from the traditional decentralized vertical management pattern based on the existing operation management process is difficult to fit, the need for improvement of the centralized management mode, so as to give full play to the advantages of cloud computing management mode.

\section{Summary}

At present, cloud computing because of its special technical features and advantages, has started its application in the next generation space test information system, operation management system as an important part of the aerospace test information system, also will be changed.

In this paper, the cloud based management model and architecture, compared with the traditional way has three advantages: First of all, the platform management into service oriented management, operation and management personnel to liberate from the traditional management platform, only need to pay attention to the operation and management of the business itself; Secondly, the decentralized management into centralized management, originally scattered in various units, the professional management of the operation focused on the cloud; Third, fixed management into place management, users can access management information in any place through various types of network terminal equipment to carry out operational management services.

At the same time, also face the challenge of platform troubleshooting difficulty and high availability of the increased demand, transportation management system process needs to be optimized. It is necessary to explore, improve and solve the problems in the process of system design, construction and application.

\section{References}

[1] Zheng Shihui etc. Create data center production and maintenance services cloud[J]. Computerize Financial Services,2013 (5):74-76.

[2] Hu Ping. Research on operation and maintenance system based on Cloud Computing Technology[J]. Telecommunications Science,2011 (12):97-102.

[3] Zhao Wangfei etc. Study on the management mode of network cloud computing[J]. Mobile Communication,2011 (6): 38-41.

[4] Ma Jian etc. Research on operation and maintenance mode of information system in cloud computing environment[J]. Electric power information and communication technology,2015,13(8):140-144.

[5] Ma Rui. Design of operation and maintenance management platform based on monitoring platform[C]. Proceedings of the 28 National Symposium on computer security.2013:75-77.

[6] Liu Yu. Design and implementation of operation and maintenance management system based on J2EE[D]. Shandong University,2015.

[7] Yuan Hongbo. Research on the impact of cloud computing application on the information architecture and operation of F company[D]. University of Electronic Science and technology of China,2015.

[8] Shi Zhanliao. The study on the innovation of management mode of electric power information system Internet plus background[D]. North China Electric Power University(Beijing),2016.

[9] Zheng Ximin. Research on information system architecture in cloud environment[D]. Harbin Institute of Technology,2015.

[10] Chen Exiang etc. Research on information security architecture in cloud computing environment[J]. Telecommunication engineering technology and standardization,2016,29(12):72-77. 